\title{
Information Technology Enabled Organizational Transformation: Toward an Integrative Theoretical Framework
}

\author{
Kyung Jin Cha ${ }^{1}$ and Joon Seub Cha ${ }^{2}$ \\ ${ }^{1}$ KeiMyung University, 1095 Dalgubeol-daero, Daegu, 704401, Korea \\ ${ }^{2}$ Honam University, 417 Euodeaung-daero, Gwangju, 506714, Korea
}

kjcha7@kmu.ac.kr,jscha7@hotmail.com

\begin{abstract}
Information Technology enabled Organizational Transformation (TTOे) persists as an important issue for researchers and practitioner of information systems.) Although the usage variety is interesting and potentially significant, the discourse surrounding OT remains poorly explicated in terms of both meaning and relationship with other related concepts. Several models have been developed in the inerature tofgcilitate understanding of the process by how information technology enables fundamental organizational transformation. On the basis of critical analysis and synthesis of available literature, this paper proposes an integrative theoretical framework that captures and extends relevant theories and concepts around IT enabled OT. The fout types, of transforming organization appearing in the quadrants of the proposed matrix are: (1) Innovative transformer, (2) Dynamic transformer, (3) Quick-run organization, and (4) Ledaning organization.
\end{abstract}

Keywords: organizational transformation, IT intermediate impact, organizational learning, complementar change

\section{Introduction}

The concept of "Information Technology enabled Organizational Transformation (ITOT)" has been with us for several decades, and today it is one of the most popular concepts in business. ITOT has become one of the most used change concepts of our time [1]. Although the usage vaniety is interesting and potentially significant, the discourse surrounding ITOT remains poprly explicated in terms of both meaning and relationship with other related concepts [2], and thereby it is not easy to arrive at a precise and generally agreed meaning of ITOT [1]. To thoroughly understand ITOT, it is necessary to review the broad definitions proposed by other research disciplines. This paper presents a conceptual review of the ITOT literature, highlighting important concepts and theories relating to ITOT proposed by various authors. The point of departure of this study is the generic concept of transformation. Most contemporary definitions appear to view transformation as making or becoming something new that starts at a specific point in time. Several studies have explored this phenomenon, alternatively referring to it as "quantum change", "second order change", "core feature change", "large scale change", and "strategic reorientation". OT is typically portrayed as being on a bigger, wider, and deeper scale than other forms of change [3]. Table 1 shows a range of definitions of OT. Differences between definitions of transformation, such as those cited in Table 1, tend to be a function of selective emphasis (i.e., elevating the motion element 
or the outcomes of transformation, the role of context, and so forth). The more common conceptualizations of transformation, however, appear to focus on the central role of time and the notion of manifest differences in pre and post change conditions or states [1].

\section{Table 1. Definitions of Organizational Transformation}

\begin{tabular}{|c|c|c|}
\hline Key Idea & Descriptions & Reference \\
\hline $\begin{array}{l}\text { Fundamental } \\
\text { change }\end{array}$ & $\begin{array}{l}\text { '.....Profound, fundamental changes in thought and actions, } \\
\text { which create an irreversible discontinuity in the experience of } \\
\text { a system' (p. 278) } \\
\text { '.........is the application of behavioral science theory and } \\
\text { practices to effect large-scale, paradigm-shifting } \\
\text { organizational change. An organizational transformation } \\
\text { usually results in totally new paradigms or models for } \\
\text { organizing performing work'(p.1) } \\
\text { '....is the process of fundamentally changing an } \\
\text { organization's processes in order to allow it to better meet } \\
\text { new challenges' } \\
\text { '...Succession of states that differ flndamentally from one } \\
\text { another' } \\
\text { 'Transfiguration from one state to another Sevies of } \\
\text { transitions with evolutionary and } \\
\text { 'the process of fundamentally changing an morganization's } \\
\text { strategy, culture, structure and processes in order to allow it } \\
\text { to better meet new challenges.' }\end{array}$ & Mill and Collins [8] \\
\hline Productivity & $\begin{array}{l}\text { '.....By organizational transformation I mean intra } \\
\text { organizational change that leaves the organization better } \\
\text { able to compete effectively in its competitive milieu' }\end{array}$ & Newman [10] \\
\hline $\begin{array}{l}\text { Discontinuous } \\
\text { change }\end{array}$ & $\begin{array}{l}\text { '.....change that is episodic, discontinuous, and intermittent' } \\
\text { '..second Conder change, multidimensional, multilevel, } \\
\text { qualitafive discontinuous, Nadical, a paradigm shift' }\end{array}$ & $\begin{array}{l}\text { Weick and Quinn [11] } \\
\text { Levy and Merry [12] }\end{array}$ \\
\hline $\begin{array}{l}\text { Broad change in } \\
\text { organizational } \\
\text { entity }\end{array}$ & $\begin{array}{l}\text { '...eframing, which is a discontinuous change in the } \\
\text { organization's or groups' shared meaning or culture. It also } \\
\text { involves broad change not only in work processes, but also in } \\
\text { other dimensions of organization, such as organizational } \\
\text { structure, Strategy, and business capabilities' } \\
\text { 'Difference, in form, quality, or state over time of } \\
\text { organizational entity' } \\
\text { 'Organizational transformation is a transition between } \\
\text { organizational states that differ substantially in crucial } \\
\text { features such as strategy and structure' }\end{array}$ & $\begin{array}{l}\text { Van de Ven and Poole } \\
{[14]} \\
\text { Wischnevsky and } \\
\text { Damanpour [15] }\end{array}$ \\
\hline $\begin{array}{l}\text { Unpredictability } \\
\text { Emergence }\end{array}$ & $\begin{array}{l}\text { "..Emergence of new and unknown state from the remains of } \\
\text { the old." } \\
\text { "...Rapid transition from one to another, sudden unexpected } \\
\text { and dramatic change." }\end{array}$ & $\begin{array}{l}\text { Ackerman [16] } \\
\text { Macintosh and } \\
\text { Maclean [17] }\end{array}$ \\
\hline
\end{tabular}

As observed in Table 1, many different definitions are available but there is no single, universally accepted, concise definition of OT. A substantial variation in the meaning of OT suggests that the most significant shortcoming of the above definitions is that they represent the thoughts of a few people based on their particular perspective, anchored in specific research studies. Each research community seems to have some preferences for different terminology, adding to the difficulties in communicating across researchers and practitioners. For instance, academics may use the term 'punctuated equilibrium' (e.g., Gersick, [18]) to refer to the same transformation dynamic that consultants may call 'radical', 'revolutionary', or 'fundamental' change. The definitions do not capture the collective wisdom of the diverse organizational research community, which is not conducive to successful transformation 
management practices. It is clear that efforts to clarify and further define the meaning of OT, leading to more agreed upon typologies and terms, would greatly improve the understanding of IT-enabled organizational transformation.

\subsection{A Shift from Revolutionary Change to Continuous Change}

Organizational change analyses, written since Porras and Silvers' review [19], suggest that an important contrast in change research is the distinction between change that is revolutionary and discontinuous, and change that is incremental, evolving, and continuous. The distinction between incremental and radical change was first articulated by Watzlawick et al., [20] and then followed by Van de Ven and Poole [14]. In its early usage, various researchers regarded OT as a synonym for revolutionary change and second-order change $[12,21,22]$. This perspective probably oriented from Levy and Merry's definition (1986, p.5) of OT as "second-order change which is amulti-dimensional, multi-level, qualitative, discontinuous, radical organizatonal change involving a paradigmatic shift". With this definition, scholars such as Marshak [7], Kmg [23], and Hill and Collins [8] continued to attach their own specific meanings to the concept of OT. For example, King's (1997) view was that OT is a planned change designed to significantly improve overall organizational performance. Hill and Collins [8] refer to OT as a transfiguration from one state to another. These authors detail OT as change that is a fundamental and "state" change, indicating change in the organizational core system. In the later 1990s, researchers started to understane that OT may have more descriptive power than radical or discontinuous change, simply) since the properties of these change concepts are far more narrowly conceived. Although the concept of planned change dominated the organizational change discourse for decades, criticisms surfaced in the form of the new 'emergent approach', large focused on challenging the episodic linear movement of change from one state to another, given the uncertainty and turbulent environment [24]. Research evidence exists that IT-enabled OT is often incremental, informal, emergent, and is based on learning through small innovations [25, 26]. Transformation is described as situated and grounded in continuing updates of social practices [27, 28]. The distinctive idea in this perspective is that small, continuous morphing, increased simultaneously across units, can accumulate and create substantial transformation within an organization [29].

Both revolutionary and incremental change theorists have proposed a number of contrasting tactics for accomplishing OT [30]. These tactics vary in the type of employee participation, scope of communication for transformation, and nature of leadership (e.8. transformational leadership) [26]. Table 2 shows that there is clear distinction between change that is revolutionary and incremental in terms of its concept, emphasis and perspective. However, the ideal organization, in both types of organizational change, resembles the successful self-organizing firms that Brown and Eisenhardt [31] found. In their study, successful firms did not rely on a purely organic process and structure. Instead, successful firms had well-defined managerial responsibilities and clear project priorities along with processes that were highly flexible, improvisational, and continuously changing. The images of organizations that are compatible with both revolutionary and continuous change include those built around the ideas of continuous change, improvisation, translation, and learning [24]. 
Table 2. Comparison of Radical and Incremental Change

\begin{tabular}{|l|l|l|}
\hline & $\begin{array}{l}\text { Revolutionary and Discontinuous } \\
\text { Change }\end{array}$ & Incremental and Continuous Change \\
\hline $\begin{array}{l}\text { Metaphor of } \\
\text { organization }\end{array}$ & $\begin{array}{l}\text { Organizations are inertial and change is } \\
\text { infrequent, discontinuous, intentional }\end{array}$ & $\begin{array}{l}\text { Organizations are emergent and self- } \\
\text { organizing, and change is constant, } \\
\text { evolving, cumulative }\end{array}$ \\
\hline Perspective & $\begin{array}{l}\text { Change is an occasional interruption or } \\
\text { divergence from equilibrium. It tends to } \\
\text { be dramatic and it is driven externally. }\end{array}$ & $\begin{array}{l}\text { Change is a pattern of endless } \\
\text { modifications in work processes and social } \\
\text { practice. Numerous small accommodations } \\
\text { accumulate and amplify. }\end{array}$ \\
\hline Emphasis & Short-run adaptation & Long-run adaptability \\
\hline Key concepts & $\begin{array}{l}\text { Deep fundamental change, replacement } \\
\text { and substitution, revolution }\end{array}$ & $\begin{array}{l}\text { Emergent patterns, improvisation, } \\
\text { translation, learning }\end{array}$ \\
\hline
\end{tabular}

A shift in vocabulary from "change" to "changing" has an important implication for understanding OT. When organizations understand the changing nature of OT, isolated small innovations can be celebrated and seen as important to a wider range of fundamental transformation.

\subsection{History of Concepts Relating to Organizational Transformation}

The concept of OT has evolved over time. In the 1980s, OT was a synonym for "second-order change" (Levy and dierry [12 , p.5), radical change, deep change, and revolutionary change. The radjcaltone of earlier understanding of OT has been somewhat tempered by a more nolistic vievof OT [33]. King [23] and Guha et al., [34] view OT as a planned change designed to significantly improve overall organizational performance (e.g., quality, responsiveness, cost, flexibility, satisfaction etc.), by changing most organizational features. Their basic assumption is that change would not be necessary if the organization thad done the job right in the first place. Such a model, which treats change as an event to be managed and planned, may have been appropriate for organizations that were relatively stable and bounded and in which functionality was sufficiently fixed toallow for detailed specification.

Later, researchers starled to define OT as fundamental change that results in substantial differences in crucial organizational features, such as structure, process, culture and capability [35]. The studies further suggest transformation comprises a series of transitions from one state to another that entail both evolutionary and revolutionary change. OT was viewed as a series of fast, mini-revolutionary changes and incremental changes [32]. It is a long innovation journey, rather than a single planned event. Since then, the term 'morphing' has also been introduced in an academic context to describe comprehensive, continuous, dynamic OT. Regardless of whether 'morphing' is the right term, it does have some advantages for describing the emerging context of OT [29]. The idea of continuous morphing is consistent with the emergent paradigm of OT, which emphasizes environmental dynamism and flexibility [28]. Rindova and Kotha [28] describe organizational transformation as "continuous morphing" and profound transformation. They include significant changes in the range of products and services offered, along with reconfiguration of the resources, capabilities, and structures employed to deliver the extended range of products and services. Relying on continuous morphing to attain OT may require significant changes in managerial thinking, and a shift in focus from planned control to opportunistic evolution and experimentation [28]. 
As such, the scope, speed, and even nature of OT seem to be changing. The history of the meaning of OT offers important insights for understanding the nature of ITenabled OT. The most important point is that researchers have started to address more holistic organizational systems, rather than parts or segments of an organization. The literature now proposed a new perspective of defining OT calling for adopting comprehensive views (e.g., the concept of balancing change with continuity [36] rather than choosing one over the other (planned vs emergent or incremental vs revolutionary).

\section{The Nature of IT-enabled Organizational Transformation}

\subsection{History of Concepts Relating to IT-enabled OT}

The meaning of IT-enabled OT has evolved over time; it is an overarching and extensive concept encompassing a range of terms including radicar and incremental change, business process re-engineering, emergent change, complementary change, and innovation and learning [37]. In the 1980s and 1990s the dominant approaches to ITenabled OT were; total quality management (TQM) and business process reengineering (BPR). TQM adopts a continuous change approach to $\mathrm{OT}$, focusing on improving overall product quality, lowering operating costs, and neduding lead time. BPR attempts to abandon existing processes in favor of radical reform [13, 38]. However, organizational change, in its various forms, had a fairly poor record throughout the 1990s. TQM and BPR [39] required massive anounts of financial and human resources, with limited returns. Such a mechanistic yiew/of IT-enabled OT, which ignores the emergent, complex, and often contradictory socio-technical interactions fundamental to IT-enabled OT, was crificized [401. Orlikowski [24] introduced the emergent perspective of IT-enâbled OT. She noted that IT-enabled OT is emergent rather than planned and suggested that ongoing adaptations and adjustments are the essence of ITenabled OT. She also proposed that there is a complex relationship of reciprocal causality between IT and QT, with the outcomes emergent and difficult to predict in advance [41]. Al the same time, the resource-based view (RBV) has been a popular theoretical lens for research on the relationship between dynamic capabilities [42] and IT-enabled OT. Among the RBV researchers, Wade and Hulland [43]'s paper emphasizes the inportance of looking at resource complementarities and moderating influences when studying the effect of information systems on organizational performance Brynjofsson and Hitt [44-45] initially proposed the importance of complementary changes enabled by IT. A more recent idea is that variation in IT value may be explained by the extent to which IT is used to enable organizational transformation [46]. Econometric IT value studies [44-45, 47-50] have indicated that organizational transformation outcomes explain the greater increases in productivity associated with IT.

\subsection{Interdisciplinary view of IT-enabled Organizational Transformation}

2.2.1. ITOT with Resource Base View (RBV): The RBV of the firm has frequently served as a theoretical foundation for understanding the locus of ITOT. According to $\mathrm{RBV}$, firm create organizational competitive outcomes on the basis of resources that are unique, valuable, and not easily imitable or substitutable [51]. Traditional RBV research centers on the relationships between IT resources themselves and business performance. This view has been criticized for its limited conceptualization, Clemons 
and Row [52], Floyd and Wooldridge [53], Powell and Dent-Meicallef [54], Zahra and Covin [55], Mata et al., [56] and Dedrick et al., [57] found that IT resources alone do not provide competitive advantage; rather, firms gain competitive advantage by leveraging complementarities among people, culture, strategy, and structure $[49,58]$. Further, Wade and Hulland [43] and Ravichandran and Lertwongsatien [59] emphasize the importance of examining resource complementarities and moderating influences when studying the effect of IT on organizational transformation. Complementarity refers to "how one resource many influence another, and how the relationship between them affects competitive performance" [43 p.123]. Teece et al., [42] referred to these complementarities as firm's unique abilities to deploy resources in combination or bundles to create a capacity for achieving a desired objective. These authors syggest that IT resources or capabilities are likely to affect organizational performance only when they are deployed to create unique complementarities with other firm resources. In the RBV literature, resource complementarities have been conceptualized in two broad ways. The first perspective conceptualizes resource complementarity based on how one resource enhances the effect of another resource, using multiplicative terms in statistical analyses. For example, Powell and Dent-Micallef [54]) used interaction terms to test the effects of complementarities between human resource practices and IT on organizational performance. Another perspective conceptualizes resource complementarity based on how resources are channeled and utilized. It is not the copresence of resources that results in complementaripes; rather, firms have choices about how resources are deployed [59]. Complementarities arise when resources are used in a mutually reinforcing manner [45]. While the complementarities between IT and other resources have been emphasized [60] in determining the contribution of IT to organizational outcomes limited work has been undertaken to examine the effects of complementarities on IT enabled organizational transformation.

2.2.2. ITOT with Organizationan learning perspective: An important element of the ITOT process is organizational learhing. In particular the concepts of exploitation and exploration are relevant in 1 TOT because they help to explain how and why a firm exploit IT and explore IT. Exploration refers to an organizational experimentation with new alternative and porsurt of knowledge about unknown opportunities. Exploitation, in contrast is considered to be the development use of things through the refinement and extension of existing resources and knowledge. Such concept was used by IS researchers such as Subramani [61] and Lee [62], they distinguishes two modes of IT use; IT exploration and IT exploitation. Furthermore, recent organizational change studies have emphasized the role of "dynamic capabilities" in facilitating fundamental organizational transformation. Dynamic capabilities have been defined as 'the firm's ability to integrate, build, and reconfigure internal and external competencies to address rapidly changing environments (Teece et al., [42], p.516). Dynamic capabilities are an appropriate perspective for developing a theory of organizational transformation in turbulent environments because they are focal to the organizational processes that enable growth and adaptation in changing environment [63]. The dynamic capabilities approach merge with a range of issues from organizational development and learning literature. However, in general the approach to ITOT is still rooted in traditional planned versus emergent mode of change. The lack of alignment between the ITOT and the OC literature suggests there is a need for interdisciplinary study to enhance the theory of of organizational transformation with respect to the impact of IT. 


\section{The IT-enabled Organizational Transformation matrix}

An analysis of the emerging thoughts and concepts on IT enabled OT indicates that although a large number of researchers acknowledge the importance of transforming with IT, very few have actually attempted to explain the nature of ITOT using validated or actionable conceptual framework. Based on the issues and dimensions reviewed above, we propose a draft conceptual framework of "IT enabled OT" on a matrix.

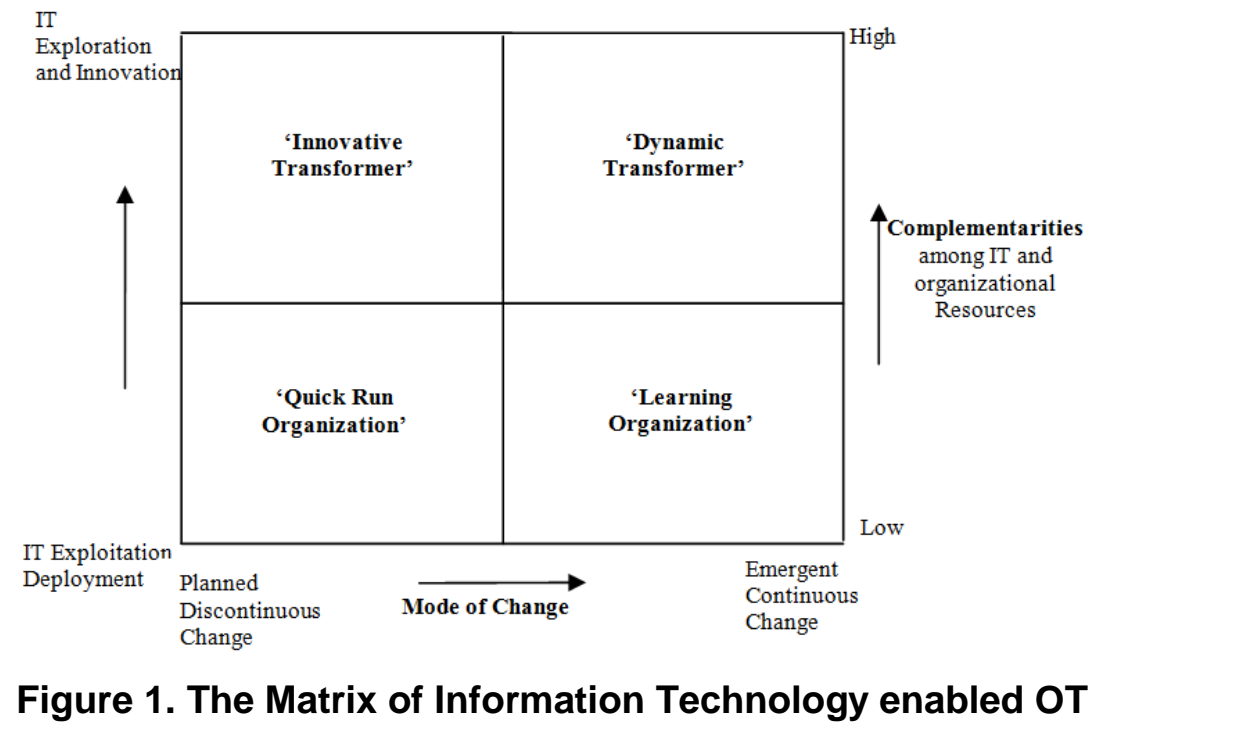

The matrix and its thre dimensions are our choice about how to synthesize and represent the findings from the literature review. The first vertical axis represents two modes of IT use: IT exploration and IT exploitation [61, 64]. In particular, IT exploitation refers to a firm's activities to adopt information technologies to improve existing process. In contrast, IT exploration refers to the firm's activities to acquire new IT to develop novel strategies for the pursuit of new possibilities. IT exploration reflects risk taking, experimentation and innovation. The second vertical axis represents degree to which-Organization achieve complementarities between IT and its organizational contexts. For fundamental transformation enabled by IT, it is essential to accompany necessary change to organizational resources such as strategies, structures, process an culture. Venkatraman et al., [65] note that the realization of IT benefits is only marginal if only superimposed on existing organizational conditions. The horizontal axis concerns the means by which mode of change is pursued. As Van de Van and Poole [14] proposed, the mode of change can be distinguished in terms of whether the change event is prescribed a priori, or whether the progression is constructed and emerges as the change process unfolds. Similarly, "Planned and Discontinuous" indicates a prescribed, intentional transformation focused on short-run adaptation. This planned mode evokes a sequence of change events in accord with a pre-established rules or program such as BPR and TQM. In contrast, the mode of "Emergent and Continuous" change is a pattern of constant, improvising, and long run adaptation. The outcome of such changes is unpredictable beforehand and there is a high degree of uncertainty and a need to make sense of the changes. The four main varieties are not seen as having hard boundaries, but rather as giving a high-level view 
of how companies can be compared in their implementation of IT enabled OT. These categories appearing in the quadrants of the matrix are:

\subsection{Quick-run Organization}

This quadrant appears to represent a radical transition from one state to another, expected change enabled by a single implementation of IT. Strong leadership take place in this quadrant, so that OT is highly controlled and planned consequences from a single IT solution such as software package and upgrade of database management system, etc. The key aim is to change processes in order to obtain improvement in lead time, quality and cost reduction. Although 'quick-run' firm can frequently achieve improved efficiency from IT, they often find it difficult to sustain because of the resulting imbalance with other organizational factors.

\subsection{Innovative Transformer}

In this quadrant, we locate a discourse of intentional change that emphasis organization-wide change through a relatively controlled or planned process. Large scale change approaches that are related with business proces reengineering and others seem characterized by a need to be omore transformed and innovate and a highly organized and planned beforehand, usually expert-led or outsourced, method leading towards ITOT as a "a rapid and revolutionary change" enabled by IT. This seems closest to us to Levy and Merry (212J's definttion of OT as "second order change, multidimensional, multilevel, discontinuous, radical, a paradigm shift". Even though the change is rapid, their focus is appropriate integration of IT with key organizational resources such as business process, strategy, quality to improve the speed of response to the market's specifie meeds and thus to enable firms to seize new opportunities by changing their existing ways of dôing things. Over the long term, small revolutionary changes may cumulate to prodace as larger transformation and their new IT initiative complements with its organizational structure, strategy culture and process. In such organization, the uncertainty) experienced by organization member is relatively low, because they typically anticipate the direction of change over the course of IT enabled OT.

\subsection{Learning Organization}

In this quadrant, ITOT involves a particular emphasis on incremental changes, and is based on learning through many small IT related innovations. Classic organizational learning hiterature (e.g., Senge,[66]) has a generative and evolutionary focus, particularly a view that "accommodations to and experiments with the everyday contingencies, breakdowns, exceptions, opportunities, and unintended consequences" [11]. The evolutionary characteristics of changes are similar to "Dynamic transformer", but the major difference is the mode of IT adoption and "absence of dynamic capabilities". In this quadrant, only IT exploitation exist which enable the organization to reconfigure, leverage and thus to develop the threshold operational capabilities for short-term survival.

\subsection{Dynamic Transformer}

In contrast with learning organization, 'dynamic transformer' moves beyond mere survival to securing sustainable competitive advantage. This quadrant represents a 
continuously adaptive organization with IT having dynamic capabilities [13], along with processes that are highly flexible, improvisational and continuously changing. In such organization, by balancing continuous and discontinuous change and the two types of learning (exploration and exploitation), organization generates dynamic capabilities in their IT adoption to acquire the strategic flexibility to adapt to changes in the environment, and thus to secure sustained competitive advantage. 'Dynamic transformer' engage in exploration learning in response to the challenges of the environment may require new business models and new creative innovation [34]. The image of dynamic transformers that are compatible with continuous emergent change and mini revolutionary change include those built around the ideas of continuous morphing [37] and learning through innovation [11]. Through situated and grounded in continuing updates of social practices, significant changes of organizational form can be occurred in such dynamic transforming organization. This is broadly consístent with Marshak [38]'s emphasis on IT enabled transformation as accumulated substantial changes to an organization's strategies, structure, process, boundaries, culture and so on through small innovations.

\section{Conclusion}

Although attention to the role of ITOT In firm' competitive success has been increasing over the past two decades, many questions remain unresolved. Theoretical perspective in the ITOT literature, such as the resources-based view, dynamic capability view, complementary perspectife and the concept of exploitation and exploration bring different understandings about the locus of and the mechanisms of firm's ITOT. This study aims to provide an integrative theoretical perspective to explain the complex nature of IT OT. The review section of this paper suggests that the definitions of OT vary, making it difficut to address the range of transformations enabled by IT. The scope, speed, and even nature of $0 \mathrm{~T}$ seem to be changing. The history of the meaning of OT suggests that researchers have started to address more encompassing organizationa sys ems, rather than parts or segments of an organization. The matrix we proposed is a synthesis and specific application to the idea of IT enabled organizational transformation. The concept of ITOT inevitably collapse similar qualitative differences that are enfolded within the term "organizational change" in general. We have argued that the meaning of IT-OT is more instructive to consider the possible purpose to which the concept is recruited, and to explore differences of usage in the literature across different disciplines.

As a coneeptual study in an organizational context, this study has potential theore vicalimitation. Most of all, within a firm, the boundaries between the contrasting mode of IT use and mode of change, such as planned versus emergent, discontinuous versus continuous and explorative versus exploitative are not always clear. However, we speculate the nature of IT enabled transformation is likely to differ markedly according to the quadrant on the matrix that represents their mode of change, mode of IT use and degree of complementarities. It is not suggesting that in practice, transformations necessarily fall into one of these pure types. It seems most likely that in practice there would be a mixture, with one quadrant perhaps dominant. The conceptual matrix may serve as building blocks for explaining processes of IT enabled OT. However, further research needed to identifies the circumstances with case examples when each type of ITOT applies and proposes how interplay among the four different categories explains the complex nature of IT enabled OT. Despite the limitation, this 
study holds benefits for both academics and practitioners. First, this study helps to enhance ITOT theories and offers insights that may provide new ways to think about the process of ITOT. This study provides a theoretical foundation for further empirical studies around ITOT. The proposed matrix enables researchers to consider different set of conditions and characteristics of each of different types of ITOT. Finally, this study offers guidance for practitioners to more strategically and selectively focus their IT investment, depending on their different levels of environmental dynamism and their own organizational internal situation, in order to more effectively enable fundamental transformation with IT. Given the matrix of the term IT-OT, we expect to find greater curiosity about its potential of IT to facilitate substantial transformation in organization form. We hope it will promote clearer and more explicit theories of ITOT and provide a foundation for future empirical research.

\section{References}

[1] C. L. VanTonder, "Organisational change: Theory and practice", Van Schaik, Pretoria, (2004).

[2] G. Dehler and M. Welsh, Journal of Managerial Psychology, vo). 9, (1994), pp. 17-26.

[3] P. Tosey and G. Robinson, The TQM Megazine, vol. 14, (2002), pp. 100-109.

[4] J. Adams, "Transforming work: A collection of organizational transformation readings", Miles River Press, Alexandria, VA, (1984).

[5] W. L. French, J. Bell, H. C and R. A. Zawacki, "Organization Development and Transformation; Managing Effective Change", Richard D. Irwin, Inc., Bøston,MA, (1994).

[6] 1. Palmer, C. Hardy, "Thinking about management: implications of organizational debates for practice", SAGE, London, (2000).

[7] R. J. Marshak, Organizational Dynamics, vol. 22, (1993), pp. 44-56.

[8] F. Hill and L. Collins, International Journal of Quality \& Reliability Management, vol. 17, (2000), pp. 966983.

[9] M. S. Scott-Morton, "The codrporation of the 1990s: Information technology and organizational transformation", Oxford Uhiversity Press, New, York, (1991).

[10] K. Newman, Academy of Management Review, vol. 25, (2000), pp. 602-619.

[11] K. E. Weick, "Organizational Redesion as Improvisation", Oxford University Press, New York, (1993).

[12] A. Levy and 6.Meny, "Organizational transformation: Approaches, strategies, theories", Praeger, New York, NY, (1986).

[13] T. Davenport, "Process innovation: reengineering work through information technology", Harvard Business School Press, Boston, (1993).

[14] A. VandeVen and M. Poole, academy of management journal, vol. 20, (1995), pp. 510-540.

[15] J. D. Wischnevsky and E. Damanpour, Journal of Managerial Issues, vol. 18, (2006), pp. 104-128.

[16] L. S. Ackerman, "Development, transition or transformation: The question of change in organizations", Jossey-Bass, San Francisco, (1997).

[17] R. Macintosh and D. MacLean, Management, vol. 23, (1999), pp. 546-564.

[18] C. J. F. Gersick, Academy of management review, vol. 16, (1991), pp. 10-36.

[19] N Venkatraman, Sloan management review, vol. 35, (1994), pp. 73-73.

[20] P. Watzlawick, J. Weakland, R. Fisch and M. Erickson, "Change: Principles of problem formation and problem resolution", Norton New York, (1974).

[21] B. M. Lichenstein, Journal of Organizational Change Management, vol. 10, (1997), pp. 393-411.

[22] W. R. Torbert, Research in Organizational Change and Development, vol. 3, (1989), pp. 83-116.

[23] M. King, Journal of Information Technology, vol. 12, (1997), pp. 131-143.

[24] W. J. Orlikowski, Information System Research, vol. 7, (1996), pp. 63-92.

[25] H. Mintzberg, Administrative Science Quarterly, vol. 24, (1979), pp. 582-589.

[26] W. L. Harkness, W. J. Kettinger and A. H. Segars, MIS Quarterly, vol. 20, (1996), pp. 349-368.

[27] H. Tsoukas, Strategic management journal, vol. 17, (1996), pp. 11-25.

[28] V. Rindova and S. Kotha, Academic Management Journal, vol. 44, (2001), pp. 1263-1280.

[29] R. Marshak, Strategic Change, vol. 11 (2002), pp. 279-286.

[30] D. Stoddard and S. Jarvenpaa, Journal of Management Information Systems, vol. 12, (1995), pp. 81-108.

[31] S. L. Brown and K. M. Eisenhardt, Administrative Science Quarterly, vol. 42, (1997), pp. 1-34.

[32] K. Weick and R. Quinn, Annual Review of Psychology, vol. 50, (1999), pp. 361-386. 
[33] V. Grover, S. Y. Jeong, W. J. Kettinger and J. T. C. Teng, Journal of Management Information Systems, vol. 12, (1995), pp. 109-144.

[34] S. Guha, V. Grover, W. J. Kettinger and J. T. C. Teng, Journal of Management Information Systems, vol. 4, (1997), pp. 119-154.

[35] P. C. Nutt and R. W. Backoff, Journal of Management Inquiry, vol. 6, (1997), pp. 235-254.

[36] S. Nasim, Sushil, Journal of Change Management, vol. 11, (2011), pp. 185-206.

[37] P. Besson and F. Rowe, The Journal of Strategic Information Systems, vol. 21, (2012), pp. 103-124.

[38] M. Hammer and J. Champy, "Reengineering the Corporation: A Manifesto for Business Revolution", HarperCollins, New York, (1993).

[39] S. Gardner and C. G. Ash, Logistics Information Management, vol. 16, (2003), pp. 18-24.

[40] V. Grover and W. Kettinger, "Process Think: Winning Perspectives for Business Change in the Information Age", Idea Group Pub, Hershey, PA, (2000).

[41] W. J. Orlikowski, ORGANIZATION SCIENCE, vol. 11, no. 4, (2000), pp. 404-428.

[42] D. J. Teece, G. Pisano and A. Shuen, Strategic Management Journal, vol. 18, (1997), pp. 509-53

[43] M. Wade and J. Hulland, MIS Quarterly, vol. 28, (2004), pp. 107-142.

[44] E. Brynjolfsson and L. Hitt, "Computing Productivity: Are Computers Pulling Theif Weight?", MIT and Wharton Mimeo, (2000).

[45] E. Brynjolfsson and L. Hitt, Communication of ACM, vol. 35, (2000) pp. 66-77.

[46] N. Melville, K. Kraemer and V. Gurbuxani, MIS Quarterly, vol 28, (2004), pp. 283-322.

[47] T. Bresnahan and S. Greenstein, Brookings paper on Economic Aotivity: Microeconomics, (1997), pp. 1-78.

[48] E. Brynjolfsson and L. Hitt, The Review of Economics and Statistics, vol. 85 (2003), pp. 793.

[49] R. J. Murnane, F. Levy and D. Autor, "Technologica-change, computers and skill demands: evidence from the back office operations of a large bank", NBER Econonic Researeh Labor Workshop, Mimeo, (1999).

[50] T. Bresnahan, E. Brynjolfsson and L. Hitt, Quâtterly Journal of Ecônopics, vol. 117, (2002), pp. 339-376.

[51] J. Barney, Journal of Management, vol. 17, (1991) pp. 99-120

[52] E. Clemons, Harvard Business Review, (2002),pp. 56-65.

[53] S. W. Floyd and B. Wooldridge, Journal of Management Inforpation Systems, vol. 7, (1990), pp. 47-64.

[54] T. Powell and A. Dent-Micallef, Strategi mlanagement journal, vol. 18, (1997), pp. 375-405.

[55] S. Zahra and J. Covin, Strategic Manadement Journal, vol. 14, (1993), pp. 451-478.

[56] F. Mata, W. Fuerst and J. Barney, MIS Quarterly, vol.P 9, (1995), pp. 487-505.

[57] J. Dedrick, V. Gurbuszni and R. Kraemer, ACM Computing surveys, vol. 35, (2003), pp. 1-27.

[58] S. Rivard, L. Raymondand D. Yerreault, Journal of Strategic Information Systems, vol. 15, (2006), pp. $29-50$.

[59] T. Ravichandran and C. Lertwongsatien, Jourhal of Management Information Systems, vol. 21, (2005), pp. 237-276.

[60] G. Ray, M. A. Muhamma and J. B. Barney, MIS Quarterly, vol. 29, (2005), pp. 625-653.

[61] M. Subramani, Mis Quarterly, vol. 28, (2004), pp. 45-73.

[62] O. K. D. Lee, Review of Business) Information Systems, vol. 16, (2012), pp. 43-52.

[63] S. E. A. Dixon, K. E. Meyer and M. Day, Journal of Management Studies, vol. 47, (2010), pp. 416-436.

[64] J. G. March, Organization science, vol. 2, (1991), pp. 71-87.

[65] J.C. Henderson, N. Venkatraman and S. Oldach, in: J.F. Luftman (Ed.), Competing in the Information Age: Strategic Alignment in Practice, Oxford University Press, New York, (1996), pp. 21-42.

[66] P. M. Senge, "The fifth Disciplines: The art and Practice of the Learning Organization", Century, London, (1990).

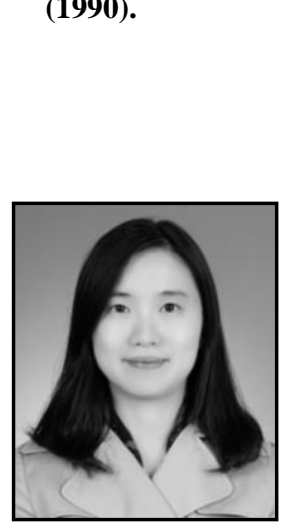

\section{Authors}

\section{Kyung Jin Cha}

She received the Honous degree in Business Information Systems from the University of Tasmania in 2006 and the $\mathrm{PhD}$ degree in Management Infomration Systems from the Australian National University in 2011. She is a Professor in the Department of Management Information Systems at KeiMyung University at Daegu, South Korea. Her doctoral dissertation focuses on understanding how organization can improve their ability to innovate and transform with IT. Her current research interests include organizational aspects of IT, IT value measure, smarwork and data mining. 


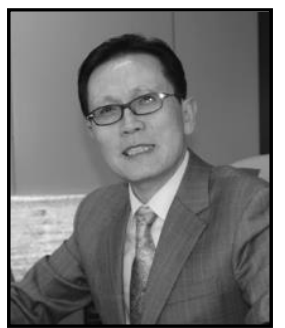

\section{Joon Seub Cha}

He received the M.S degree in Computing Science from the Dongguk University in 1982 and the $\mathrm{PhD}$ degree in Management Infomration Systems from WonKwang University in 1995. He is a Professor in the Department of Internet Contents at Honam University at Gwangju, South Korea. His current research interests include System Analysis and design, SmartMedia, SmartValley, SmartWork, Big Data.

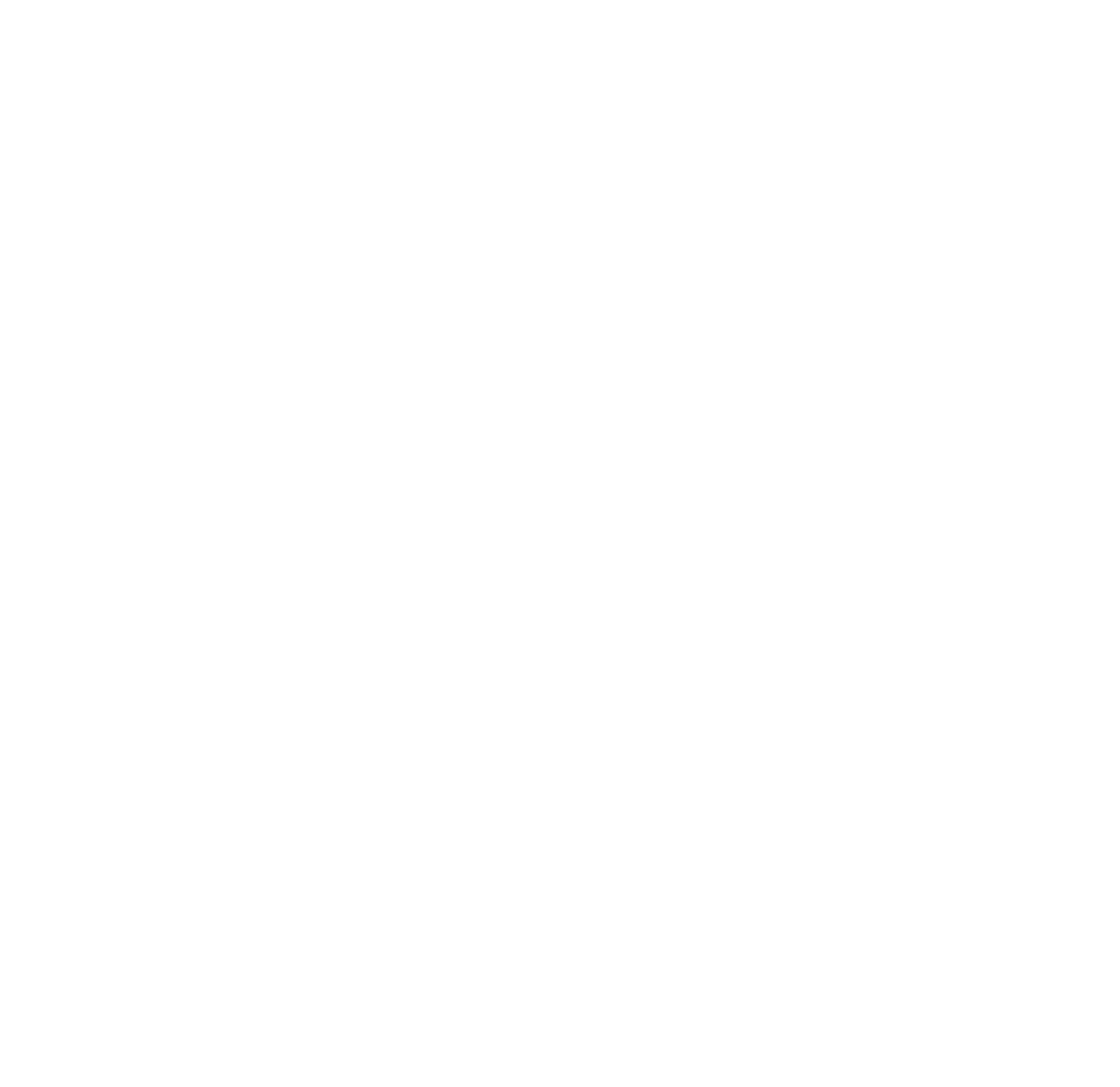

